\title{
Fabrication of Anchored Complexes as Electrodes for Sensing Heavy Metal Ions by Electrochemical Method
}

\author{
JEMINI JOSE ${ }^{1}$, RIYA DATTA ${ }^{1}$ and SREEJA P $B^{1^{*}}$ \\ 'Department of Chemistry, Christ University, Hosur Road, Bangalore 560029, India. \\ "Corresponding author E-mail: sreeja.pb@christuniversity.in
}

http://dx.doi.org/10.13005/ojc/330346

(Received: May 09, 2017; Accepted: May 31, 2017)

\begin{abstract}
Anchored coordination complexes as electrochemical sensors play a significant role in the modern era. It is evident that this becomes a fact on account of their practical convenience. Furthermore, they have unlimited scope in ecological, therapeutic, experimental and biomedical applications. It has been observed that 165 such papers have reported on anchored complexes for electrochemical sensing during the past two years. While human vitality is rigorously threatened by heavy metal ions today, numerous trials are restrained for screening these in nature. This retrace highlights the electro analytical methods and the masterpiece contribution of anchored coordination complexes as electrochemical sensors for the identification of heavy metals such as indium, uranium, lead, beryllium, and mercury in 2015 and 2016.
\end{abstract}

Keywords: Molecularly imprinted polymers, ion-imprinted polymers, DNAzyme functionalized nanoparticle.

\section{INTRODUCTION}

Chemical sensors have a vital role in promoting the speedy development of electrochemical sensors in smart chemistry. They deliver ever lasting information about their environment. Ultimately, a chemical sensor affords an exact kind of reaction which imparted to the scope of the particular class of chemical compounds. All chemical sensors form a transducer. It helps the mutual conversion of the response into a sensible sign on the exactroutes, and a chemically selective film. In addition, it separates the reaction of the analyte from its expeditious situation. In the beginning of the present century, research on electrochemical sensor fabrication has made radical changes in the integrable arena of science. Referred to miscellaneous sensors, electrochemical sensors have dominant position owing to their significant sensibility, tentative easiness, minimum expenditure and its relevances in various disciplines. Because of the non-biodegradability and proliferation of heavy metal ions in tissues, they are observed as the fundamental basis to fade the biosphere and affect the physical well-being of human kind $^{1-3}$. Diverse systems such as electrochemical ${ }^{4}$, mass spectrometric ${ }^{5}$ and optical 
methods ${ }^{6}$ have been exaggerated for the exposition of the ions. The presence of substantial metal particles causes the alteration of the capacitance, current flow, electrochemical impedance, and electroluminescent methods which are capable of utilized for their investigation ${ }^{7,8}$. The approaches like potentiometry, capacitance, electrochemical impedance, amperometry and electroluminescence are derived from these ascertaining signals. By modified functionalization and construction, these materials can be brought together in the exterior part of an electrode for the assembly of appropriate electrodes. It also assists the susceptible and selective detection of heavy metal ions. The setting up of various materials has widened the electrochemical achievements. For concrete illustration, polymers or biomaterials are regularly come together on inorganic nanomaterials to manufacture the highly responsive electrochemical sensors for heavy metal ions ${ }^{9-18}$. Because of the potential for the small analytical period, less engine capacity, valuable sensitivity and simple adaptability for in-situ extent ${ }^{19}$,electrochemical detection methods using anchored complexes have attracted enormous attention in the detection of heavy metal ions. This review summons up the formulation and sensing means such as the molecularly imprinted polymers, ion-imprinted polymers, exploitation incentive responses of a deoxyribozyme (DNAzyme), fluorescence and complexes with conducting nation binders for heavy metal ions in 2015 and 2016are briefly explained.

\section{Detection Of Metal Ions Detection Of Indium}

Indium is the fragile and flexible constituent engrossing in the design of high purity materials, semiconductor enterprises and atomic studies ${ }^{20-22}$. Moreover, indium salts presume a decisive part in insoluble batteries. It can be blended with the footprints of minerals like sphalerite and is usually acquired as a result of zinc mining. Physiologically, composites of indium harm various living functions of human body. S. Kagaya et al., 2009, incorporated inductively coupled plasma spectroscopy to produce excited atoms for determination of the element after co-precipitation with indium sulphate ${ }^{23}$ as vindication. E.Kazemi et al., 2011, found the satisfactory results of indium in a water sample and standard alloys with liquid-liquid micro extraction fibre optic linear array detection spectroscopy ${ }^{24}$. The another attempt to enhance the sensitivity using slotted quartz tube atom-trap-flame atomic absorption spectrometry was suggested by Arslan, 201125. Yang et al., 2010, achieved the measurements of isotope ratios of indium, and Karadas et al., 2011, detected the presence of indium in sea water using multi-collector inductively coupled plasma mass spectrometry ${ }^{26,27}$ Optical strategies ${ }^{28,29}$ and electrochemical method ${ }^{30}$ are employed for the determination of indium. Nevertheless, numerous issues are encountered in handling these techniques. The specimen of indium is isolated from tin, silicon, tellurium and sulphate particles by flame atomic absorption spectroscopy at the time of atomization stage $^{31}$. Volatilization shrinkage in the atomization procedure brought on high temperature equally bring about the lower outcome than the original strength $^{32}$.Stripping voltammetric and polarographic strategies have weak distinction toward constituents of resembling zenith position of indium ${ }^{33}$.Besides, the essence of indium in experiments is subtle; hence, establishing an exact explanatory strategy to mark out indium is entirely critical. Zhang et al., 2015, proposed highly selective molecularly imprinted electrochemical sensor for the detection of $\ln ^{3+}$ by using Indium Alizarin red $\mathrm{S}$ compound acting as a support molecule comprehended through the vacant spaces in the molecularly imprinted polymer ${ }^{34}$ and is illustrated in scheme 1

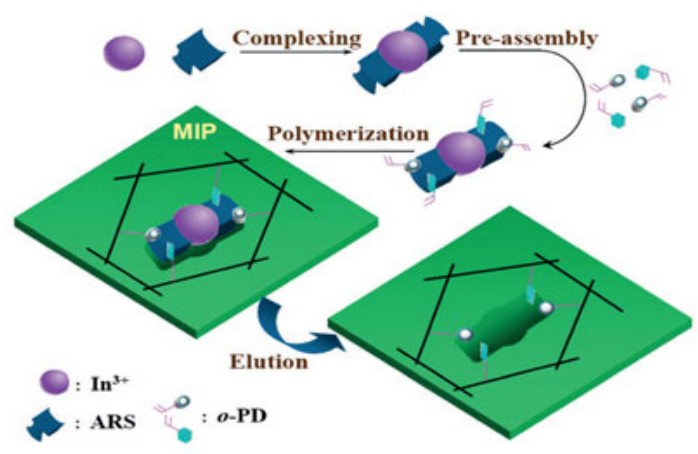

\section{Scheme 1: Molecular imprinting detection of In $^{3+}$ ions based on metal-ligand chelate- oriented recognition Ref ${ }^{34}$}

The selectivity of the sensor was enhanced altogether because of the particular threedimensional constitution of the mixture and the specific complexation of ligands for metal particles. Besides, the affectability of the sensor has been progressed by noting the declining current of ligand 
in the composite. The procedure was profoundly sensitive for quantitative investigation of $\mathrm{In}^{3+}$ in the fixations going from $1 \times 10^{-8} \mathrm{~mol} / \mathrm{L}$ to $2.5 \times 10^{-7} \mathrm{~mol} / \mathrm{L}$ with recognition boundary of $4.7 \times 10^{-9} \mathrm{~mol} / \mathrm{L}$ which was lower than commonly used methods. The proposed sensor has been effectively utilized as a part of identifying $\ln ^{3+}$ in positive specimens ${ }^{34}$.

\section{Detection Of Uranyl lon}

The spoliation of uranium is usually of distinct sorts of soils and stones. Additionally, it can be procured from excavation and fabrication. Its corrupt nature increases the responsibility of distinguishing such tainting in water. Estimation of uranium fixation is having an incredible significance in atomic production because of the use of the metal as fuel in fission reactions. Different strategies have been utilized to decide Uranyl particles fixation. The spectrometric procedure is employed to evaluate uranyl in ocean water ${ }^{35,36}$ and adsorption of uranium by polarographic technique ${ }^{37}$. The constitutional effects of the $\mathrm{UO}_{2}$ complex with bulky groups were inspected through nuclear magnetic resonance spectrometry ${ }^{38}$. The drawbacks of these promulgated systems $\mathrm{s}^{35-38}$ contrive a requisite to build up a quick, delicate and authentic strategy for uranium resolution in different fragments. Zamani et al.,2012manufactured a potentiometric sensor of pristine gadolinium for lanthanide sequence deduction ${ }^{39}$ and aterminalofneodymium (III) was built by Menon et al.,201140. A variety of ligands has been utilized to set up the uranyl sensors such as 1-(4-carboxyphenyl)-1H-1,2,3-triazole-4carboxylic $\operatorname{acid}^{41}$ and crown ether ${ }^{42}$. Shokrollahiet al.,2009, ${ }^{43}$ arranged and concentrated on the anodes criterion for uranyl sensors rely on bis (2-hydroxy acetophenone) ethylene diimine. Bader et al., 2012 created uranyl layer terminals based on amino ( tri-methyl) phosphate ${ }^{44}$ and the formed film cathodes observed to be specific in the vicinity of uranyl particle over a vast number of impeding cations. Metilda et al., 2004 ${ }^{45}$ arranged particle engraved polymer materials for uranyl particle by framing binary 5,7-dichloroquinoline-8-ol (DCQ) or 4-vinylpyridine.Molecularly imprinted polymers have been tailored and thoroughly described for the detection of uranyl ion. M.A.Abu-Dalo et al., 2016, displayed another uranyl electrochemical sensor by adopting acrylic acid as a monomer; ethylene glycol dimethacrylateas a cross coupling agent and benzoyl peroxide as an initiator. The boosted polymer was promoted by magnetic material; Uranyl-carboxy benzotriazole complex. The comfortable situation for the format particle rebinding can be produced by keeping up the complex genome-attempt through the cross-linking and discharging velocity. A few uranyl cathodes were developed by handling distinctive masses of polyvinyl chloride frame work. Cathode tape measures including inclines, working focuses, $\mathrm{p}^{\mathrm{H}}$, and obstructions were assessed. The terminals show an extensive variety of fixation from $3 \times 10^{-6}$ to $6 \times 10^{-2} \mathrm{M}$ and sensibility of $1 \times 10^{-6} \mathrm{M}$. The impact of $\mathrm{Cr}^{3+}, \mathrm{La}^{3+}, \mathrm{Ba}^{2+}, \mathrm{Ca}^{2+}, \mathrm{Cu}^{2+}, \mathrm{Na}^{+}$and $\mathrm{K}^{+}$ particles impedances on the cathode reaction were assessed. The coupling limit and stability dissolution variables were dictated by contemplating the coupling isotherm. The combinations of uranyl particle in the fabricated settlements controlled by the expansion technique and the outcomes were agreeable with deviation lower than $7 \%$.At last, the sensor was tried to decide the uranyl particles focuses in water test by standard expansion technique ${ }^{46}$.

\section{Detection Of $\mathrm{Be}^{2+}$}

Beryllium is a deceptive cancer-causing poison because of its trouble in biodegradation ${ }^{47}$. It can be recognized by means of atomic absorption and emission spectrometry ${ }^{48}$ and fluoro spectrometry ${ }^{49}$. In any case, techniques either lack affectability and selectivity or need costly mechanical assembly and entangled investigation. Moreover, the sensing may be upset by the intervening blends in tests. Therefore, it is imperative to formulate adequate and precise location technique for ultra-proof beryllium in water and other provisions. Electro chemilumine scence sensors have great responsive quality ${ }^{50}$. Molecularly imprinted polymer sensors through electrochemilumin escent estimation could encourage the receptivity and exclusive exposition with a quite clear specimen a pre-treatment strategy ${ }^{51,52}$. The intricate particle is bestowed as the layout atom to copolymerize with the monomer and frame sensor. Jianping Li et al.,2015 $25^{5}$ has picked the compound of $\mathrm{Be}^{2+}$ with 4-(2-Pyridylazo)-resorcinol (PAR) as the layout atom for the molecularly imprinted polymer. After the purification of the compound, the moulded engraved depressions could function as the passage for analysis to achieve the surface of the anode and create electrochemilumine scence. With the holes retrieved by the composites, the ECL force is diminished. The mechanism of the sensor is shown in Scheme $2 \operatorname{Ref}^{53}$ 
The depressions framed could further perform as the blunt for the exchange for test atoms to deliver echo alert indication. The certainty

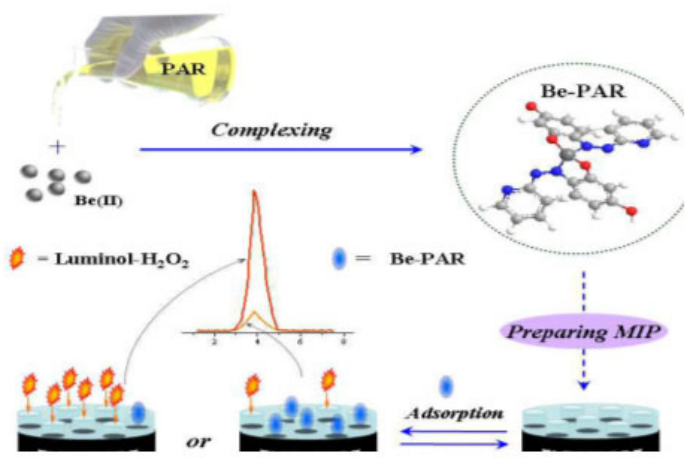

depended on the strength of the symbol, which was corresponding to the convergences of the composites in the specimen arrangement, and the $\mathrm{Be}^{2+}$ fixation could then be resolved implicitly. The outcomes demonstrated that in the span of $7 \times 10^{-11} \mathrm{~mol} / \mathrm{L}$ to $8.0 \times 10^{-9} \mathrm{~mol} / \mathrm{L}$, the electrochemilumin escent strength hada. direct association with the $\mathrm{Be}^{2+f i x a t i o n s, ~ w i t h ~ t h e ~ p o i n t ~ o f ~ c o n f i n e m e n t ~ o f ~}$ $2.35 \times 10^{-11} \mathrm{~mol} / \mathrm{L}$. The strategy is profoundly ideal and delicate, with minimal effort and great steadiness to spot $\mathrm{Be}^{2+}$ in water. It is anticipated to give another system to manufacture molecularly imprinted polymer sensors for the identification of other metal particles.

\section{Detection Of Lead}

Among the hazardous substances, lead is known to prompt an expansive scope of physiological, biochemical, and behavioural dysfunctions in creatures, which incorporate troubling the frameworks of the heart, blood, nerve, kidneys and liver ${ }^{54}$. The massive impairment of these metal particles to the earth, physique and sustainment, have created a basic need for creating productive detecting frameworks that are susceptible and concrete, as well as exact cost effective, and sensible ${ }^{1,55}$.Over previous decades, various spectroscopic techniques ${ }^{56-62}$ and different synthetically adapted electrodes ${ }^{63-68}$ have come up with the evaluation of $\mathrm{Pb}^{2+}$. The estimation of these systems is precisely not reasonable due to their convoluted and massive instruments. While analyzing these strategies, it is found that the electrochemical techniques have been pulled in more prominent consideration in the most recent two decades on account of their minimal effort, simple operation, and the capacity for examining the component speciation. The outline and usage of the silver-based coordination compounds have conquered the expanding consideration in the last decades ${ }^{69-71}$ owing to their intriguing atomic structures, as well as their characteristic properties. The geometrical adaptability of silver (1) brings about the elaborate coordination models and exhibits a chance to investigate the features like an assembly of metal and ligands containing many donor atoms, the ratio of metal and ligand and counter particles in coordination combinations ${ }^{72,73}$. Yangjuan Wanget al.,2016,was integrated, an organized pattern of the donor ligand of nitrogen, carboxylic acid and metal salts of silver $(1)^{74}$. The differential pulse anode stripping voltammetric method is employed to find out the minute levels of lead and selectivity of the complex in exact figuration with high accuracy. The stripping current is gained with the amount of lead and the location cut off is $8.0 \times 10^{-10} \mathrm{~mol}^{-L^{-1}} . \mathrm{In}$ spite of slight aggregation time, themelanine/silver nitrate/terephthalic acid terminal is bounded by a lesser threshold of evaluation and extensive direct range of the maximum cathodes assessed other than the bismuth film adjusted electrode ${ }^{75}$. Plaxco and collaborators have employed deoxyribonucleic acid/gold bio standardized keys to accomplish sign intensification for the lead in nano molar level ${ }^{76}$. Yang et al.,2010 77 additionally facilitated the discovery of lead availing functionalized gold nanoparticles with DNA zyme as a method for enhancement, empowering as far as possible to be $0.028 \mathrm{nM}$.Zeng and group have bestowed a carboxylic acid family functionalized multiwall carbon nanotubes /AuNPsadjusted anode and exploiting $\mathrm{Pb}^{2+}$ generated G-rich DNA conformation, with maximum restriction of $4.3 \times 10^{-6} \mathrm{nM}^{78}$. Nevertheless, the reported electrochemical lead diagnosing techniques require complex and multistep conventions. Introducing nanoporous gold cathode as a strong support for the immobilization of probe DNA and implementing an appropriately constructed, catalytically existing gold nanoparticle framework to accomplish signal improvement were researched. Cheng Zhang et al.,2016 ${ }^{79}$ depicted a boosted technique reinforcing nanoporous Au (NPG) and gold nanoparticles (AuNPs) to distinguish $\mathrm{Pb}^{2+}$ particles in water. The procedure is given in Scheme 3

Schematic presentation of the apta sensor preparation and the proposed mechanism for the $\mathrm{Pb}^{2+}$ detection. 


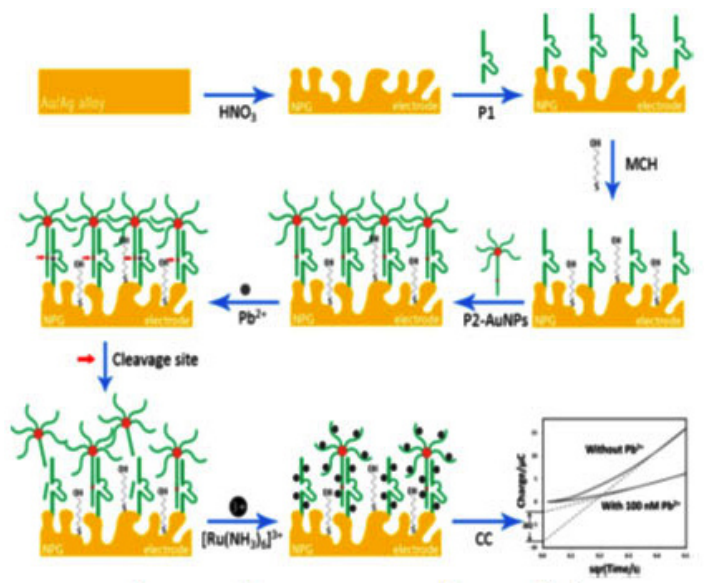

P 1 ( p r o b e 1): $5^{1}-\mathrm{SH}$ - ( C H 2 ) 6 - T T T C A T C T C T T C T C C GAGCCGGTCGAAATAGTGAGT- $3^{1}$,

P2(Probe2): $5^{1}-\mathrm{SH}-(\mathrm{CH} 2) 6-\mathrm{ACT}$ CACTATARGGAAGAGATG-3 ${ }^{1} \mathrm{P} 1$ is the $\mathrm{Pb}^{2+}$ specific DNA, and P2 is the substrate oligonucleotide, hexaammine ruthenium (III) chloride (RuHex) and $\mathrm{MCH}$ is 6-mercaptohexanol Ref ${ }^{79}$.

For the hybridization of gold nanoparticles named oligonucleotide and framing of the two-fold helix structures of DNA, the thiol altered $\mathrm{Pb}^{2+}$ catalytically active DNA molecule was arranged onto the surface of the organized nanoporous gold terminal. They used chronocoulometry to evaluate DNA coating thickness using measuring redox charge of ruthenium hexammine at surfaces, and it was adopted to figure out immobilized DNA. The

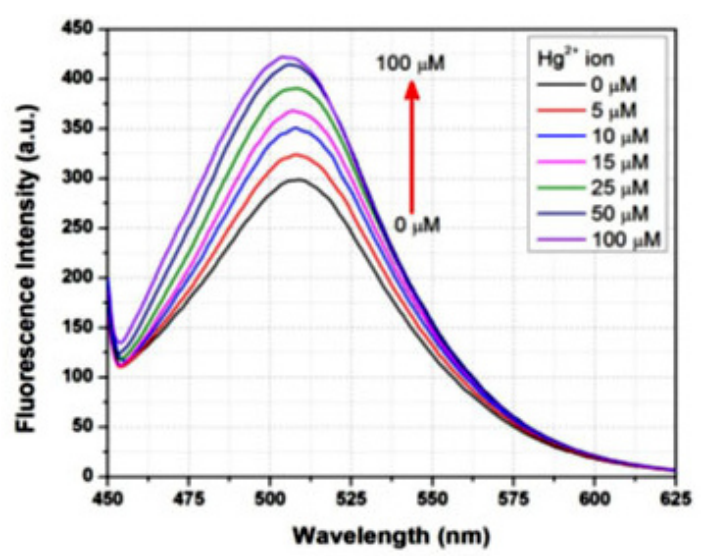

state of the subsequent chronocoulogram can be comprehended by allowing for the fixation slopes in the arrangement adjoining the anode surface and could distinguish $\mathrm{Pb}^{2+}$ by exploiting intensification impacts of the nanoporous gold cathode. For expanding the response location of assessment and DNA-Au NPs composites for realizing the adsorption of vast quantities of hexaammine ruthenium atoms in the scope of $0.05-100 \mathrm{nM}$, with a snapping point of recognition as low as $0.012 \mathrm{nM}$. Selectivity estimations uncovered that the sensor was particular for $\mathrm{Pb}^{2+}$ even with impedance on significant amounts of other metal particles. In the investigation with the conventional $\mathrm{Pb}^{2+}$ sensor, aptasensor depends on the measure of surface limited DNA switch, which is sovereign with the unique structures like G-quadruplex ${ }^{78}$, hairpin ${ }^{76}$,or stem loop ${ }^{80}$.Moreover,the intensification framework of apta sensor maintains a strategic distance from the tedious synthetic methodology, phenomenal selectivity and reproducibility.

\section{Detection Of Mercury}

As a result of the diverse types of pollution through mercury ${ }^{81}$, there has been a developing enthusiasm for extraordinarily elegant and precise materials for detecting mercuric particles in the course of recent years. Different sensor materials ,for example, natural fluorescent and colour responsible functional group compounds ${ }^{82-84}$, organic conjugated macromolecule substances ${ }^{85,86}$, metal nanoparticles ${ }^{87-89}$, biopolymers of nucleotides and aminoacids ${ }^{90-93}$ DNAzymes ${ }^{91}$ and fractions of nanometer materials ${ }^{94,95}$ have been

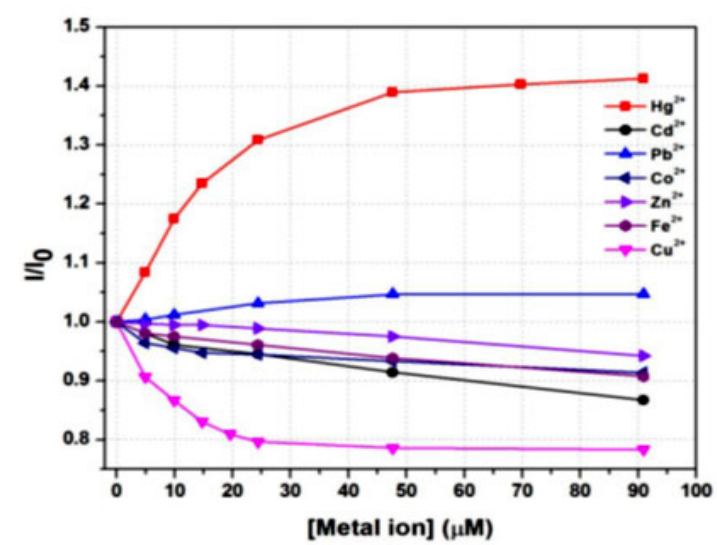

Fig. 1: demonstrates change in the fluorescence power of the complex upon accumulation of $\mathrm{Hg}^{2+}$ particle $\left(\mathrm{HgCl}_{2}\right)$ 
accounted for identification of $\mathrm{Hg}^{2+}$. On the other hand, the majority of these cases have restrictions in choice, susceptibility and feasibility. Cheng et al.,201496resolved the mercury species colorimetrically by utilizing gold nanoparticles activated with diethyldithiocarbamate in the $\mathrm{Cu}^{2+}$ particle. Xiao et al.,201597, latelyestimated a very specific discovery of methyl-mercury cation in fish tests using $\mathrm{Ag}^{0} / \mathrm{Hg}^{0}$ amalgamation. In a while, optical detecting of the metal particle was accounted for by Zhe and colleagues ${ }^{98}$,in the light of semiconductor quantum dots. The writers outlined the thought to make water solvent quantum dots is to trade the local natural ligands topped on the quantum dots surface with other dissolvable ligands utilizing peripheral charge and nonpolar cooperations. On the other hand, there are still shortcomings, for example, obstruction from another metal particle ${ }^{99,100}$ or permanent response ${ }^{82}$.Shortly,fluorescencesupported detecting materials for harmful metal particles seems to be prominent amongst the most encouraging procedures because of its high aptitude and great affectability ${ }^{101}$.The nearness of ultra-low grouping of the analyte is adequate for the eye in recognising elevation of fluorescence. The profit of this course of action is that it imposes just a couple microgram of the sensor material and it doesn't pay out many analytes and no reference material ${ }^{102}$.Besides, a couple of phosphorescence sensors were additionally created for detecting $\mathrm{Hg}^{2+103-105}$.Nilam Sing et al.,2016 ${ }^{106}$ reported the detecting property of complex $\mathrm{C}_{48} \mathrm{H}_{96.8} \mathrm{~N}_{12} \mathrm{O}_{22.4} \mathrm{Co}_{2} \mathrm{Cl}_{2}$ towards the metal particles like $\mathrm{Hg}^{2+}, \mathrm{Cd}^{2+}, \mathrm{Pb}^{2+}, \mathrm{Co}^{2+}, \mathrm{Zn}^{2+}, \mathrm{Fe}^{2+}$ and $\mathrm{Cu}^{2+}$. Isolate a liquots were set up holding a balanced tincture of complex and expanding quantities of a metal particle and fluorescence of the subsequent blend was determined.

Fluorescence emission spectra of complex 1 in aqueous solution upon addition of increasing amount of $\mathrm{Hg}^{2+}(=425 \mathrm{~nm})$. The concentration of $\mathrm{Hg}^{2+}$ in the medium is indicated in the legend; the arrow shows the growth of fluorescence intensity with the increase of the concentration of the $\mathrm{Hg}^{2+}$ ion Ref ${ }^{106}$.

Fig 1shows that at every expansion of $\mathrm{Hg}^{2+}$ particle, fluorescence power promotes to a vast degree. $\mathrm{AtHg}^{2+}$ concentration of $100 \mu \mathrm{M}$ the fluorescence power increments by $\sim$ half. Strangely, aside from $\mathrm{Hg}^{2+}$, no other metal particles can bring a notable improvement of fluorescence. This outcome obviously shows a specific detecting of $\mathrm{Hg}^{2+}$ by Co II complex. Subsequently, the present compound was observed to be an accurate sensor for $\mathrm{Hg}^{2+}$ in liquid beginning at a focus as low as $\sim 0.25 \mu \mathrm{M}$. Despite the fact that as far as possible, this case is not very cheap, in any event, the bright point of the compound is that it demonstrates turn on ensign in the proximity of $\mathrm{Hg}^{2+}$ divergent to the majority of the reports on $\mathrm{Hg}^{2+}$ detecting. Additionally, the ejection wavelength range is utterlyan evident area which opens plausibility for observing through eyes.

\section{CONCLUSION}

This review discussed anchored complexes which help to detect the aforesaid compounds like indium, uranium, beryllium, lead and mercury being an electrochemical sensor. What is more, it has also described regarding the research in this recent two years mentioning the fabrication, sensitivity and the benefits compared to other analytical methods. Everybody isata race to make out the pure water. This motivates researchers to identify heavy metal ions in water. However, it is miserable that they have reached only at the micro and nano level. Most of the work above mentioned are in the water like medium or aqueous medium and this review may help the researcher to extend the work to the aqueous medium and thereby living organism. Therefore, it is forecasted that if they are able to investigate the parts per million levels of the above ions, it will be a considerable asset to the mankind.

\section{REFERENCES}

1. Kemper, T.; Sommer, S. Environ. Sci. Technol. 2002, 36 (12), 2742.

2. Tu, C.; Shao, Y.; Gan, N.; Xu, Q.; Guo, Z. Inorg. Chem. 2004, 43 (15), 4761.
3. Tuzen, M.; Melek, E.; Soylak, M. J. Hazard. Mater. 2006, 136 (3), 597.

4. Aragay, G.; Merkoi, A. Electrochim. Acta 2012, 84, 49. 
5. Ugo, P.; Zampieri, S.; Moretto, L. M.; Paolucci, D. Anal. Chim. Acta 2001, 434 (2), 291.

6. Kim, H. N.; Ren, W. X.; Kim, J. S.; Yoon, J. Chem. Soc. Rev. 2012, 41 (8), 3210.

7. Combellas, C.; Kanoufi, F.; Pinson, J.; Podvorica, F. I. J. Am. Chem. Soc. 2008, 130 (27), 8576.

8. Fan, L.; Chen, J.; Zhu, S.; Wang, M.; Xu, G. Electrochem. commun. 2009, 11 (9), 1823.

9. Chey, C. O.; Ibupoto, Z. H.; Khun, K.; Nur, O.; Willander, M. Sensors (Basel). 2012, 12(11), 15063.

10. Gong, T. Z. J.; Song, D.; Zhang, L.; Hu, X. Anal. Chem. 2010, 82 (2), 567.

11. He, X.; Su, Z.; Xie, Q.; Chen, C.; Fu, Y.; Chen, L.; Liu, Y.; Ma, M.; Deng, L.; Qin, D.; Luo, Y.; Yao, S. Microchim. Acta 2011, 173 (1-2), 95.

12. Kong, R.-M.; Zhang, X.-B.; Zhang, L.-L.; Jin, X.-Y.; Huan, S.-Y.; Shen, G.-L.; Yu, R.-Q. Chem. Commun. (Camb). 2009, No. 37, 5633.

13. Liu, M.; Zhao, G.; Tang, Y.; Yu, Z.; Lei, Y.; Li, M.; Zhang, Y.; Li, D. Environ. Sci. Technol. 2010, 44 (11), 4241.

14. Pan, D.; Wang, Y.; Chen, Z.; Lou, T.; Qin, W. Anal. Chem. 2009, 81 (12), 5088.

15. Sanchez, A.; Morante-Zarcero, S.; PerezQuintanilla, D.; Sierra, I.; Del Hierro, I. Electrochim. Acta 2010, 55 (23), 6983.

16) Wang, L.; Xu, M.; Han, L.; Zhou, M.; Zhu, C.; Dong, S. Anal. Chem. 2012, 84, 7301"7307.

17. Sudibya, H. G.; He, Q.; Zhang, H.; Chen, P. ACS Nano 2011, 5 (3), 1990.

18. Tang, S.; Tong, P.; Li, H.; Tang, J.; Zhang, L. Biosens. Bioelectron. 2013, 42 (1), 608.

19. Wong, E. L. S.; Chow, E.; Justin Gooding, J. Electrochem. commun. 2007, 9 (4), 845.

20. Ferreira, E. D. M. M.; Morelli, T.; Moreira, I. M. N. S.; De Carvalho, M. S. J. Braz. Chem. Soc. 2004, 15 (4), 563.

21. Acar, O.; Kiliç, Z.; Türker, A. R. Anal. Chim. Acta 1999, 382 (3), 329.

22. Ferreira, S. L. C.; Andrade, M. G. M.; Lobo, I. P.; Costa, A. C. S. Anal. Lett. 1991, 24 (9), 1675.

23. Kagaya, S.; Mizuno, T.; Tohda, K. Talanta 2009, 79 (2), 512.

24. Kazemi, E.; Shokoufi, N.; Shemirani, F. J. Anal. Chem. 2011, 66 (10), 924.
25. Arslan, Y.; Kendüzler, E.; Ataman, O.Y. Talanta 2011, 85 (4), 1786.

26. Yang, L.; Sturgeon, R. E.; Mester, Z.; Meija, J. Anal. Chem. 2010, 82 (21), 8978.

27. Karadao, C.; Kara, D.; Fisher, A. Anal. Chim. Acta 2011, 689 (2), 184.

28. Gnihotri, N. K. A.; Atnani, S. R.; Ingh, V. K. S.; Ingh, H. B. S. 2003, 19 (September), 2.

29. Huseyinli, A. A.; Alieva, R.; Haciyeva, S.; Güray, T. J. Hazard. Mater. 2009, 163 (2-3), 1001.

30. Bobrowski, A.; Putek, M.; Zarebski, J. Electroanalysis 2012, 24 (5), 1071.

31. Acta, C.; Chemistry, A.; Motu-umcmachi, C.; Prefecture, O. 1975.

32. Volynsky, a. Spectrochim. Acta Part B At. Spectrosc. 2000, 55 (2), 103.

33. Chumbimuni-Torres, K. Y.; Calvo-Marzal, P.; Wang, J. Electroanalysis 2009, 21 (17-18), 1939.

34. Zhang, L.; Li, J.; Zeng, Y.; Meng, L.; Fu, C. 2015, 1758.

35. Konstantinou, M.; Pashalidis, I. Mediterr. Mar. Sci. 2004, 5 (1), 55.

36. Smith, N. A.; Cerefice, G. S.; Czerwinski, K. R. J. Radioanal. Nucl. Chem. 2013, 295 (2), 1553.

37. Inam, R.; Çaykara, T.; Kantolu, O. /. Nucl. Instruments Methods Phys. Res. Sect. B Beam Interact. with Mater. Atoms 2003, 208 (1-4), 400.

38. Amato, M. E.; Ballistreri, F. P.; Pappalardo, A.; Tomaselli, G. A.; Toscano, R. M. Molecules 2010, 15 (3), 1442.

39. Ecjhao, C.; Zamani, H. A. L. I.; Behmadi, H. 2012, 9 (1), 308.

40. Menon, S. K.; Modi, N. R.; Patel, B.; Patel, M. B. Talanta 2011, 83 (5), 1329.

41. Knope, K. E.; Cahill, C. L. CrystEngComm 2011, 13, 153.

42. Kakhki, R. M. Z.; Rounaghi, G. Mater. Sci. Eng. C 2011, 31 (8), 1637.

43. Shokrollahi, a; Ghaedi, M.; Montazerozohori, M.; Khanjari, N.; Najibzadeh, M. 2009, 812.

44. Badr, I. H. A.; Zidan, W. I.; Akl, Z. F. Electroanalysis2012, 24 (12), 2309.

45. Metilda, P.; Mary Gladis, J.; Prasada Rao, T. Anal. Chim. Acta2004, 512 (1), 63.

46. Abu-dalo, M. A.; Al-rawashdeh, N. A. F.; Al-mheidat, I. R.; Nassory, N. S. Sensors 
Actuators B. Chem.2016, 227, 336.

47. Larivière, D.; Tremblay, M.; Durand-Jézéquel, M.; Tolmachev, S. Anal. Bioanal. Chem.2012, 403 (2), 409.

48. Beiraghi, A.; Babaee, S. Anal. Chim. Acta 2008, 607 (2), 183.

49. Ji, X.; Shi, W.; Zhang, S.;Wei, M.; Evans, D. G.; Duan, X. Anal. Chim. Acta 2012, 728, 77.

50. Laser, D.; Bard, A. J. J. Electrochem. Soc.1975, No. 5, 632.

51. Li, S.; Tao, H.; Li, J. Electroanalysis 2012, 24 (7), 1664

52. Li, J.; Li, S.; Wei, X.; Tao, H.; Pan, H. 2012.

53. Li, J.; Ma, F.; Wei, X.; Fu, C.; Pan, H. Elsevier B.V. 2015.

54. Matoviæ, V.; Buha, A.; Dukiæ-Æosiæ, D.; Bulat, Z. Food Chem. Toxicol. 2015, 78, 130.

55. Darwish, I. A.; Blake, D. A. Anal. Chem. 2002, $74(1), 52$.

56. Leopold, K.; Foulkes, M.; Worsfold, P. J. TrAC - Trends Anal. Chem. 2009, 28 (4), 426.

57. Pourreza, N.; Parham, H.; Kiasat, A. R.; Ghanemi, K.; Abdollahi, N. 2009, 78, 1293.

58. Bagheri, H.; Afkhami, A.; Saber-Tehrani, M.; Khoshsafar, H. Talanta 2012, 97, 87.

59. Taylor, P.; Afkhami, A.; Madrakian, T.; Siampour, H. No. May 2013, 37.

60. Afkhami, A.; Saber-Tehrani, M.; Bagheri, H. J. Hazard. Mater. 2010, 181 (1-3), 836.

61. Li, Y.; Jiang, Y.; Yan, X. P.; Ni, Z. M. Environ. Sci. Technol. 2002, 36 (22), 4886.

62. Mas, J. L.; Villa, M.; Hurtado, S.; GarcíaTenorio, R. J. Hazard. Mater. 2012, 205-206, 198.

63. Morante-Zarcero, S.; Pérez-Quintanilla, D.; Sierra, I. J. Solid State Electrochem. 2015, $19(7), 2117$.

64. Arantes, T. M.; Sardinha, A.; Baldan, M. R.; Cristovan, F. H.; Ferreira, N. G. Talanta 2014, 128, 132.

65. Kim, H. J.; Son, D. W.; Park, J. M.; Hwang, D. Y.; Mo, C. Y.; Park, S. W.; Kim, G.; Eun, J. B. Food Sci. Biotechnol. 2010, 19 (5), 1211.

66. Lu, Y. Y.; Chen, M. N.; Gao, Y. L.; Yang, J. M.; Ma, X. Y.; Liu, J. Y. Fenxi Huaxue/ Chinese J. Anal. Chem. 2015, 43 (9), 1395.

67. Jasmin, J. P.; Cannizzo, C.; Dumas, E.; Chaussé, A. Electrochim. Acta 2014, 133, 467.

68. Wang, Y.; Wu, Y.; Xie, J.; Hu, X. Sensors
Actuators, B Chem. 2013, 177, 1161.

69. Wang, C. C.; Wang, P.; Guo, G. L. Transit. Met. Chem. 2012, 37 (4), 345.

70. Chen, C. L.; Kang, B. S.; Su, C. Y. Aust. J. Chem. 2006, 59 (1), 3.

71. Wang, C. C.; Wang, P.; Guo, G. S. Transit. Met. Chem. 2010, 35 (6), 721.

72. Tong, M. L.; Wu, Y. M.; Ru, J.; Chen, X. M.; Chang, H. C.; Kitagawa, S. Inorg. Chem. 2002, 41 (19), 4846.

73. Ni, J.; Wei, K. J.; Liu, Y.; Huang, X. C.; Li, D. Cryst. Growth Des. 2010, 10 (9), 3964.

74. Manuscript, A. 2016.

75. Kachoosangi, R. T.; Banks, C. E.; Ji, X.; Compton, R. G. Anal. Sci. 2007, 23 (3), 283.

76. Baker, B. R.; Lai, R.Y.; Wood, M. S.; Doctor, E. H.; Heeger, A. J.; Plaxco, K. W. J. Am. Chem. Soc. 2006, 128 (10), 3138.

77. Yang, X.; Xu, J.; Tang, X.; Liu, H.; Tian, D. Chem. Commun. (Camb). 2010, 46 (18), 3107.

78. Zhu, Y.; Zeng, G. M.; Zhang, Y.; Tang, L.; Chen, J.; Cheng, M.; Zhang, L. H.; He, L.; Guo, Y.; He, X. X.; Lai, M. Y.; He, Y. B. Analyst 2014, 139 (19), 5014.

79. Zhang, C.; Lai, C.; Zeng, G.; Huang, D.; Tang, L. Biosens. Bioelectron .2016, 81, 61.

80. Ke, C.; Huang, C.; Fan, C. 2003.

81. Harris, H. H.; Pickering, I. J.; George, G. N. Science (80-. ). 2003, 301 (5637), 1203.

82. Yang, Y. K.; Yook, K. J.; Tae, J. J. Am. Chem. Soc. 2005, 127 (48), 16760.

83. Nolan, E. M.; Lippard, S. J. J. Am. Chem. Soc. 2007, 129 (18), 5910.

84. Ando, S.; Koide, K. 1980, No. li, 1.

85. Kim, I. B.; Bunz, U. H. F. J. Am. Chem. Soc. 2006, 128 (9), 2818.

86. Dave, N.; Chan, M.Y.; Huang, P. J. J.; Smith, B. D.; Liu, J. J. Am. Chem. Soc. 2010, 132 (36), 12668.

87. Lee, J. S.; Han, M. S.; Mirkin, C. A. Angew. Chemie - Int. Ed. 2007, 46 (22), 4093.

88. Xue, X.; Wang, F.; Liu, X. 2008, 3244.

89. Li, D.; Wieckowska, A.; Willner, I. Angew. Chemie - Int. Ed. 2008, 47 (21), 3927.

90. Ono, A.; Togashi, H. Angew. Chemie - Int. Ed. 2004, 43 (33), 4300.

91. Liu, J.; Lu, Y. Angew. Chemie - Int. Ed. 2007, 46 (40), 7587.

92. Hollenstein, M.; Hipolito, C.; Lam, C.; Dietrich, 
D.; Perrin, D. M. Angew. Chemie - Int. Ed .2008, 47 (23), 4346.

93. Chen, P.; He, C. J. Am. Chem. Soc. 2004, 126 (3), 728.

94. Brainina, K. Z.; Stozhko, N. Y.; Shalygina, Z. V. J. Anal. Chem. 2002, 57 (10), 945.

95. Palomares, E.; Vilar, R.; Durrant, J. R. Chem. Commun. (Camb). 2004, No. December 2003, 362.

96. Chen, L.; Li, J.; Chen, L. ACS Appl. Mater. Interfaces 2014, 6 (18), 15897.

97. Deng, L.; Li, Y.; Yan, X.; Xiao, J.; Ma, C.; Zheng, J.; Liu, S.; Yang, R. Anal. Chem. 2015, 87 (4), 2452.

98. Lou, Y.; Zhao, Y.; Chen, J.; Zhu, J.-J. J. Mater. Chem. C2014, 2 (4), 595.

99. Šandor, M.; Geistmann, F.; Schuster, M. Anal. Chim. Acta 1999, 388 (1-2), 19.
100. Hallale, O.; Bourne, S. A.; Koch, K. R. 2005, 1416.

101. Li, M. J.; Ko, C. C.; Duan, G. P.; Zhu, N.;Yam, V. W. W. Organometallics2007, 26 (25), 6091.

102. Lakowicz, J. R. Kluwer Acad. Publ. 2002, 3.

103. Zhao, Q.; Cao, T.; Li, F.; Li, X.; Jing, H.; Yi, T. Society 2007, No. lii, 2077.

104. Ru, J. X.; Guan, L. P.; Tang, X. L.; Dou, W.; Yao, X.; Chen, W. M.; Liu, Y. M.; Zhang, G. L.; Liu, W. S.; Meng, Y.; Wang, C. M. Inorg. Chem. 2014, 53 (21), 11498.

105. Ru, J.; Chen, X.; Guan, L.; Tang, X.; Wang, C.; Meng, Y.; Zhang, G.; Liu, W. Anal. Chem. 2015, 87 (6), 3255.

106. Sing, N.; Roy, S.; Guin, P. S.; Mahali, K.; Majee, P.; Mondal, S. K.; Mahata, P.; Sengupta, P. S.; Mondal, P. New J. Chem. 2016, 40 (7), 6396. 